\title{
REVIEW
}

\section{Gut Microbiota Modulation: Implications for Infection Control and Antimicrobial Stewardship}

\author{
Glorijoy Shi En Tan $\cdot$ Hui Lin Tay $\cdot$ Sock Hoon Tan $\cdot$ Tau Hong Lee \\ Tat Ming Ng $\cdot$ David Chien Lye (1)
}

Received: June 12, 2020 / Published online: August 7, 2020

(c) The Author(s) 2020

\begin{abstract}
The human microbiome comprises a complex ecosystem of microbial communities that exist within the human body, the largest and most diverse of which are found within the human intestine. It has been increasingly implicated in human health and diseases, demonstrably playing a critical role in influencing host immune response, protection against pathogen overgrowth, biosynthesis, and metabolism. As our understanding of the links between the gut microbiota with host immunity and infectious
\end{abstract}

Digital Features To view digital features for this article go to https://doi.org/10.6084/m9.figshare.12689891.

G. S. E. Tan · T. H. Lee · D. C. Lye $(\bowtie)$

National Centre for Infectious Diseases, Singapore,

Singapore

e-mail: david_lye@ncid.sg

G. S. E. Tan - T. H. Lee - D. C. Lye

Department of Infectious Diseases, Tan Tock Seng

Hospital, Singapore, Singapore

H. L. Tay · S. H. Tan · T. M. Ng

Department of Pharmacy, Tan Tock Seng Hospital,

Singapore, Singapore

T. H. Lee - D. C. Lye

Lee Kong Chian School of Medicine, Singapore,

Singapore

T. H. Lee - D. C. Lye

Yong Loo Lin School of Medicine, Singapore,

Singapore diseases deepens, there is a greater need to incorporate methods of modulating it as a means of therapy or infection prevention in daily clinical practice. Traditional antimicrobial stewardship principles have been evaluated to assess their impact on the gut microbiota diversity and the consequent repercussions, taking into consideration antibiotic pharmacokinetic and pharmacodynamic properties. Novel strategies of selective digestive decontamination and fecal microbiota transplantation to regulate the gut microbiota have also been tested in different conditions with variable results. This review seeks to provide an overview of the available literature on the modulation of the gut microbiota and its implications for infection control and antimicrobial stewardship. With increased understanding, gut microbiota profiling through metataxonomic analysis may provide further insight into modulating microbial communities in the context of infection prevention and control.

Keywords: Antimicrobial Infection control; Infectious diseases; Gut Microbiota 


\section{Key Summary Points}

Strategies to limit the negative effects of antibiotics on the gut microbiota include restricting the duration and spectrum of antibiotic use.

Different routes of antibiotic administration have varying effects on the gut microbiota due to pharmacokinetic parameters, and these effects should be considered.

There is insufficient evidence to recommend the routine use of selective oral decontamination and selective digestive decontamination to reduce the risks of nosocomial pneumonia in critically ill patients.

The use of fecal microbiota transplants and probiotics have some role in restoring the gut microbiota diversity in the setting of dysbiosis, but require further study.

Gut microbiota profiling through metataxonomic analysis may provide further insight into modulating microbial communities in the context of infection prevention and control.

\section{INTRODUCTION}

Our knowledge of the human microbiome has increased over the past decade. It comprises a complex ecosystem of microbial communities that exist within the human body. The largest and most diverse of these exists within the human intestine. Collectively known as the gut microbiota, they have increasingly been found to play a significant role in the maintenance of human health and the development of diseases [1]. The human microbiome was first characterized by The Human Microbiome Project sponsored by the National Institutes of Health [2]. Using high-throughput sequencing, the human lower intestinal microbiota has been estimated to contain at least $10^{11-12}$ microorganisms per gram of content, comprising mainly anaerobes, more than $90 \%$ of which belong to the phyla Firmicutes and Bacteroidetes [3, 4]. Its composition is highly variable, changing with age, diet, and geographic distribution [5].

In recent years, increased understanding and analysis of the gut microbiota have shed light on the impact of alterations in it on human health. It plays a critical role in influencing host immune response, protection against pathogen overgrowth, biosynthesis, and metabolism [1]. There are implications for health and diseases even from birth [6]. Additionally, the gut microbiota serves as an important reservoir of antibiotic resistant genes, also known as the "resistome", which can become an amplifier of antimicrobial resistance [7].

As our understanding of the link between the gut microbiota with host immunity and infectious diseases increases, there is a greater need to incorporate methods of modulating it as a means of therapy or infection prevention in daily clinical practice. However, much of the available data are in the realm of in vitro data or animal studies. This review seeks to provide an overview of the available literature on the modulation of the gut microbiota, and its implications for infection control and antimicrobial stewardship. This article is based on previously conducted studies and does not contain any studies with human participants or animals performed by any of the authors.

\section{GUT MICROBIOTA AND ANTIMICROBIAL STEWARDSHIP}

In this section, we review antimicrobial stewardship strategies and evaluate their impact on the gut microbiota and the development of antibiotic resistance.

\section{Narrowing Antibiotic Spectra and Limiting Duration Of Use}

Antibiotic use reduces the diversity of the gut microbiota through the elimination of 
susceptible strains that make up normal flora. This can subsequently lead to the overgrowth of resistant or potentially pathogenic bacteria, increasing the risk of infection, especially with multidrug-resistant organisms (MDRO) $[8,9]$. The degree to which the microbiota is affected varies with the type and duration of the antibiotic used [10]. Anti-anaerobic antibiotics have a great impact on the gut microbiota as anaerobes form a significant proportion of it $[8,11]$. It has been shown that just $4-8$ days of piperacillin-tazobactam for intra-abdominal infections resulted in a substantial decrease in anaerobic commensals [11]. A study by Hecker et al. reported that anaerobic cover accounted for about $35 \%$ of the 576 unnecessary antimicrobial days of therapy [12]. Inappropriate use of anti-anaerobic antibiotics can increase the likelihood of colonization by resistant organisms [13]. In a randomized clinical study comparing the use of piperacillin-tazobactam versus ertapenem, the resistance of Enterobacterales to piperacillin-tazobactam developed at a significantly higher rate compared with ertapenem [14]. Several studies have demonstrated that newer fluoroquinolones such as levofloxacin and moxifloxacin had greater ecological effects on Gram-positive organisms than ciprofloxacin [15-17].

Logically, advocating the prescription of narrower spectrum antibiotics whenever appropriate should reduce disruption of the microbiota and resultant opportunistic infections, such as Clostridiodes difficile infection (CDI) and fungal infections. Benefits were demonstrated in the comparison of vancomycin and fidaxomicin in the management of $C$. difficile diarrhea. Fidaxomicin exposure had a smaller impact on microbiota composition in mice and conferred higher colonization resistance to $C$. difficile spores compared with vancomycin [18]. Consequently, this was associated with a lower recurrence rate in patients treated with fidaxomicin compared with vancomycin [19]. A study by Lew et al. suggested that classical antimicrobial stewardship strategies, specifically switching to narrower spectrum antibiotics, antibiotic cessation once treatment is completed, or when there is no bacterial infection, can reduce rates of antibiotic resistance and CDI [20]. This concurred with Tay et al. who reported the usage of carbapenem as a risk factor for severe CDI [21].

Excessively prolonged antibiotic use is a global concern $[12,22,23]$, and can lead to significant alteration in the gut microbiota, restoration of which can take months to years $[24,25]$. Conversely, shorter antibiotic duration results in less collateral damage to the gut microbiota, and allows for earlier restoration. Late-preterm infants who received longer courses of antibiotics had more prolonged alterations in their gut microbiota compared with those who received a shorter duration [26]. There is increasing evidence that a shorter duration of antibiotics of less than 8 days for commonly encountered infections, such as skin and soft tissue infection [27] and male urinary tract infections [28], are not associated with increased treatment failures. Antibiotic stewardship principles of making an accurate diagnosis of infection, appropriate antibiotics, and a shorter duration of antibiotic treatment or prophylaxis, would reduce unnecessary antibiotic exposure to the gut microbiota without compromising patient outcomes [29].

\section{Exploiting Antibiotic Pharmacokinetics}

The route, dose, and excretion of antibiotics affect the gut microbiota differently. Zhang et al. compared oral versus intravenous tetracycline and ampicillin using murine models, and recovered higher copies of resistant genes in mice fed with oral antibiotics compared with those which received intravenous antibiotics [30]. Lower tetracycline doses were associated with slower resistance development with fewer copies of resistant genes being isolated [30]. When clindamycin was administered via the oral route, a higher concentration of clindamycin were found in feces compared to when administered via an intravenous route. This resulted in a greater reduction of anaerobic colonic flora, leading to an overgrowth of clindamycin-resistant bacteria, such as enterococci and $C$. difficile [8].

However, compared with oral agents that are highly absorbed and excreted minimally 
through the bile or feces, intravenous antibiotics that undergo enterohepatic re-circulation or are excreted through bile, feces, or secreted into the intestinal tract may have a greater impact on the gut microbiota [31]. Various studies have found that imipenem and meropenem are excreted minimally in fecal samples after administration, and minor changes to the gut microbiota when administered for a limited duration (6-11 days) have been observed $[32,33]$. Oral penicillin was also reported to have a low fecal concentration, with almost no change in microflora [8]. In contrast, ceftriaxone, a broad-spectrum cephalosporin with high biliary excretion, effectively suppressed Enterobacterales [34]. Among macrolides, erythromycin has lower absorption from intestines compared with clarithromycin. About $95 \%$ of erythromycin versus $60-70 \%$ of clarithromycin is metabolized in the liver and excreted in bile as its active form [35]. This explains the higher impact of erythromycin on intestinal microflora [36].

In light of the above, antibiotic prescribers should firstly, only start antibiotics in the presence of a clear indication. Secondly, prescribers should choose the narrowest spectrum antibiotic available for treatment to reduce the impact on the gut microbiota (e.g., the omission of anaerobic cover if not indicated). Thirdly, antibiotics should be prescribed for the shortest duration to allow the recovery of the gut microbiota as soon as possible, and finally, oral antibiotics should be used if possible to reduce line-related infections and reduce hospitalization days. Oral agents that are highly absorbed and excreted minimally through the bile or intestinal tract are preferred. Prescribers will also need to consider the resistance potential of antibiotics. Although carbapenems are excreted minimally through the gut with a smaller impact on the gut microbiota, antibiotic prescribers should be aware of the association between carbapenem use and the increase in carbapenem resistance, which should limit its use $[37,38]$. Additionally, other factors, such as side effects, allergies, and penetration to the site of infection, will also need to be considered during prescribing, in addition to the impact of antibiotics on the gut microbiota.

\section{Targeted Local Antibiotic Delivery}

The use of non-systemic antibiotics for localized infections may help to minimize the impact on the gut microbiota and the development of antibiotic resistance. Getting the drug to only where it is needed in high concentrations is a concept that has been used in some infections. Inhaled antibiotics have been used for respiratory infections in patients with cystic fibrosis [39]. Studies have been conducted for other respiratory infections, such as pneumonia, infective exacerbation of chronic obstructive pulmonary disease, and non-cystic fibrosis bronchiectasis, but there has been a paucity of good quality studies and the outcomes have been modest [39]. Palmer et al. reported a reduced need for systemic antibiotics in the treatment of ventilator-associated tracheobronchitis with the use of inhaled antibiotics [40]. However, another study by Rattanaumpawan et al. did not observe additional benefit when using inhaled colistin as adjunctive therapy in ventilator-associated pneumonia [41]. In the clinical practice guidelines published by the Infectious Diseases Society of America (IDSA) and the American Thoracic Society in 2016, the expert panel concluded that there is a need for better quality studies to look for optimal dosing as well as aerosol delivery [42]. Local administration of antibiotics in the form of antibioticimpregnated cement and antibiotic powder have been explored over the years for the treatment or prevention of bone and joint infections [43]. Further research is needed in the area of localized administration of antibiotics in the treatment of infections to reduce the impact on the gut microbiota while achieving optimal patient outcomes.

\section{GUT MICROBIOTA MODULATION FOR INFECTION PREVENTION}

Colonization resistance is the ability of the healthy microbiota to prevent expansion of potential pathogenic bacteria [44]. Maintaining or re-establishing colonization resistance by 
modulating the gut microbiota to prevent infection have been evaluated. The next section discusses how this can be achieved.

\section{Fecal Microbiota Transplant (FMT)}

The intestine is a reservoir for MDRO that can be opportunistic pathogens selected for by antibiotic pressure, especially in critically ill and hospitalized patients [45]. Studies have shown that patients colonized with MDRO are at risk of developing infections that arise endogenously, or may transmit them to other individuals $[46,47]$. These pathogens may translocate across a damaged intestinal barrier, or result in contamination to cause infections at other sites, such as central line infections or catheter-related urinary tract infections. The gut microbiome thus serves as a prime target for infection prevention strategies, giving rise to increased interest for use of fecal microbiota transplant (FMT) and selective digestive decontamination as infection control strategies to reduce carriage of MDRO.

FMT has been found to be one of the most effective ways to regulate the gut microbiota. It was first described in 1958 [48] and has since gained increased acceptance as a medical intervention in recent decades. Eiseman et al. observed that the administration of fecal enemas resulted in dramatic responses in critically ill patients with pseudomembranous colitis [48]. It usually involves the transfer of processed stool from a healthy donor into the colon of a recipient, and is delivered enterally either endoscopically or via oral capsule preparations. This presumably allows the donor's microbiome to repopulate the gut with a healthy microbiome to restore gut dysbiosis.

At present, recurrent CDI is the only indication for which FMT has been proven to be efficacious, and it is recommended when appropriate antibiotic therapies have failed [49]. Cure rates in this group of patients were up to $90 \%$ with repeated FMT in randomized controlled trials [50-52]. Engraftment of specific bacteria and viruses with physiologic effects within the gut was thought to play a significant role in reversing dysbiosis [53]. Cheng et al. demonstrated in a piglet model that FMT had several effects on metabolic pathways that occurred within the gut to improve gut mucosal barrier integrity [54].

A number of case reports and case series have described successful decolonization of MDRO as a primary outcome among patients treated with FMT [55]. These reports included both immunocompetent and immunocompromised patients colonized with carbapenemase-producing Enterobacterales [56, 57], vancomycinresistant enterococci (VRE) [58] and extended spectrum ß-lactamase-producing Enterobacterales [59]. Unfortunately, these studies were often uncontrolled with high levels of heterogeneity and short follow-up periods, resulting in no conclusive evidence to support the safety and efficacy of FMT in this regard.

In addition to the clinical implications on patient outcome, the successful decolonization of MDRO via FMT may have several infection control implications. It reduces the burden on healthcare facilities to provide isolation rooms for such patients who require contact precautions and allows re-entry into long-term care facilities that would otherwise not have the adequate infection control resources to care for these patients [60] (see Table 1).

\section{Selective Oropharyngeal \\ Decontamination (SOD) and Selective Digestive Decontamination (SDD)}

Selective oropharyngeal decontamination (SOD) has gained interest as an infection prevention strategy in critically ill patients in the intensive care unit (ICU). In the 1960s, Johanson et al. observed that the prevalence of Gramnegative bacteria in the pharyngeal flora increased markedly within a few days of hospitalization [70]. It was postulated that, since the pathogenesis of bacterial pneumonia began with the aspiration of the oropharyngeal contents into the lung, altering the pharyngeal flora in ill patients may be important to prevent pneumonia secondary to Gram-negative bacilli.

In the 1980s, Stoutenbeek et al. introduced the concept of selective digestive decontamination (SDD) in the ICU population [71]. Given 
Table 1 Summary of key concepts in modulation of the gut microbiota in infection prevention and control and antimicrobial stewardship

\begin{tabular}{|c|c|c|}
\hline Domain & Key concepts & $\begin{array}{l}\text { Key } \\
\text { references }\end{array}$ \\
\hline \multirow[t]{4}{*}{ Antimicrobial Stewardship } & $\begin{array}{l}\text { Broad-spectrum antibiotics can cause significant alteration to the gut microbiota } \\
\text { diversity, in particular those with anti-anaerobic activity }\end{array}$ & {$[8,11]$} \\
\hline & Alterations to the gut microbiota by antibiotics take months to years to restore & {$[24,25]$} \\
\hline & $\begin{array}{l}\text { Shorter duration of antibiotic is equally effective than prolonged use and can } \\
\text { reduce alterations to the gut microbiota }\end{array}$ & {$[26-28]$} \\
\hline & $\begin{array}{l}\text { Oral antibiotics and intravenously administered antibiotics that undergo } \\
\text { enterohepatic re-circulation and excretion into bile have a greater impact on } \\
\text { the gut microbiota compared to intravenous antibiotics alone }\end{array}$ & {$[30-33]$} \\
\hline \multirow[t]{4}{*}{$\begin{array}{l}\text { Infection Prevention and } \\
\text { Control }\end{array}$} & $\begin{array}{l}\text { Fecal microbiota transplant has been found to be one of the most effective ways } \\
\text { to regulate the gut microbiota dysbiosis in the setting of CDI }\end{array}$ & {$[49]$} \\
\hline & $\begin{array}{l}\text { Fecal microbiota transplant has been studied in gut decolonization of MDRO, } \\
\text { but has not conclusively been found to be effective }\end{array}$ & {$[55,56,58]$} \\
\hline & $\begin{array}{l}\text { Selective oral decontamination and selective digestive decontamination with oral } \\
\text { antibiotics has been evaluated as a means of reducing infections caused by } \\
\text { endogenous MDRO, but has not been found to be efficacious }\end{array}$ & {$[61-63]$} \\
\hline & $\begin{array}{l}\text { Restoration of the gut microbiota diversity through probiotics and prebiotics } \\
\text { have some role in restoring gut diversity in specific diseases, such as necrotizing } \\
\text { enterocolitis, acute infectious diarrhea and antibiotic-associated diarrhea }\end{array}$ & [64-69] \\
\hline
\end{tabular}

that most infections in the ICU are primary endogenous infections, reducing bacterial load within the gastrointestinal tract, in particular potentially pathogenic microorganisms, would theoretically reduce infection risks. In SDD, enteral antibiotics are selected for their inability to be absorbed into the systemic circulation, and are active against the most common nosocomial pathogens within the gut (e.g., Escherichia coli, Klebsiella pneumoniae, and Pseudomonas aeruginosa).

Unfortunately, a randomized trial conducted in 13 European ICUs among patients receiving mechanical ventilation found that SOD and SDD were not associated with reductions in ICU-acquired bloodstream infections caused by multidrug-resistant Gram-negative organisms compared with standard care [61]. In addition, a study conducted in ICUs in the Netherlands demonstrated the "rebound phenomenon" that SOD and SDD had on the gut microbiota, with increased rates of ceftazidime resistance in the intestinal tract after discontinuation of SDD.

A combination of both interventions has been considered. A randomized trial reported no significant reduction in extended-spectrum $\beta$-lactamase or carbapenemase-producing Enterobacterales intestinal carriage between patients who received a 5-day course of oral antibiotics followed by frozen FMT obtained from unrelated healthy donors and controls [62]. In view of the lack of conclusive evidence of the efficacy of FMT and SDD, the European clinical guidelines do not recommend routine decolonization of third-generation cephalosporin-resistant and carbapenem-resistant Enterobacterales carriers [63]. 


\section{Pre-Operative Oral Antibiotic Preparation (OAP)}

Extrapolating the principles of SDD, the role of the gut microbiota in the development of surgical site infections (SSI) has been considered in colorectal surgery where surgeons operate in a cleancontaminated field. Oral antibiotic preparation (OAP) with variable combinations of aminoglycoside, macrolide, and metronidazole have been used to evaluate if they reduced rates of SSI, surgical complications of anastomotic leak, and length of hospital stay [72]. A network metaanalysis of randomized controlled trials revealed that OAP alone was not associated with a statistically significant reduction in SSI [73]. Koskenvuo et al. similarly reported no reduction in SSI or overall morbidity in colon surgery when mechanical and oral antibiotic bowel preparations were used compared with no bowel preparation [74]. There is no strong evidence to suggest that OAP as pre-operative prophylaxis is effective in reducing SSI.

\section{Probiotics and Prebiotics}

Probiotics are "living microorganisms which when administered in adequate amounts confer a health benefit on the host" [75]. Prebiotics are non-viable substrates that are selectively utilized as nutrients by beneficial microorganisms, both indigenous and exogenously administered strains, thereby conferring a health benefit [76].

Current literature shows effective reduction of colonization by Gram-positive organisms through the use of probiotics. Manley et al. and Szachta et al. both reported that VRE in the gut can be significantly reduced even to the point of eradication through oral consumption of Lactobacillus rhamnosus GG [77, 78]. Gut colonization of $S$. aureus including methicillin-resistant S. aureus was reduced after 4 weeks of oral Lactobacillus rhamnosus HNO01 in a recent clinical trial [79]. However, this beneficial effect of probiotics was not in Gram-negative MDRO in hospitalized patients and residents in long-term healthcare facilities [80, 81].

Randomized controlled trials have shown positive effects on gut health by probiotics in a myriad of conditions, such as infectious and antibiotic-associated diarrhea (AAD), irritable bowel syndrome, and enterocolitis [64]. Lactic-acid bacteria, such as Lactobacillus and yeast-based Saccharomyces boulardii (cerevisiae) probiotics, are the commonest choices for treatment of gastrointestinal conditions [79-81].

Our knowledge of the effects of prebiotics are evolving. Human studies which used-high throughput sequencing demonstrated stimulation of Bifidobacteria in response to prebiotic use $[82,83]$. In these studies, there were variations in other microorganisms, with increased Faecalibacterium prausnitzii [83] and Anaerostipes spp, whereas Bilophila spp. decreased [82]. Although proof of causality is difficult to determine, the beneficial effects of prebiotics have been evidenced through numerous randomized controlled trials, albeit variable as a result of both environmental and host factors [76].

\section{Probiotics in Necrotizing Enterocolitis (NEC)}

Necrotizing enterocolitis (NEC) is a debilitating gastrointestinal disorder in neonates characterized by transmural inflammation and bowel necrosis. Bacterial invasion of the bowel walls can occur, and empirical treatment with broadspectrum antibiotics forms part of the backbone of management [84]. Morbidity and mortality are high [85]. NEC most frequently occurs in neonates who are preterm or have very low birth weight $[65,66]$. They are inherently at a higher likelihood of receiving antibiotics due to their susceptibility to infections, and prolonged antibiotic use is a known risk factor for NEC [86]. The growth of gut-friendly commensal $\mathrm{Bi}$ fidobacteria is greatly compromised [86, 87]. Consistent benefits of probiotics in the prevention of NEC have been extensively described in systematic reviews and meta-analyses [65-67]. Sawh et al. reported that, when compared with placebo, probiotics reduced the incidence of severe NEC in 38 trials $(10,520$ patients) [RR $0.53,95 \%$ CI (0.42-0.66)] [66]. The incidence of all-cause mortality was significantly reduced with probiotics in 29 trials (9507 patients) [RR 0.79 , 95\% CI (0.68-0.93)] [86]. As such, probiotics may have a role in reducing the occurrence 
of NEC, and thus antibiotic usage and potential negative outcomes caused by NEC.

\section{Probiotics in acute infectious diarrhea and antibiotic-associated diarrhea}

Acute infectious diarrhea is one of the leading reasons for antibiotic prescription. Reduction in diarrheal incidence, severity, and duration through probiotic use may reinforce antimicrobial stewardship principles of reducing antibiotic prescriptions. Probiotics have been heavily studied in patients with acute infectious diarrhea and evidence of its benefits is well described [88, 89]. A Cochrane review of 63 studies, mainly in infants and young children, reported an average reduction of 1 day in the duration of diarrhea, reduction in the likelihood of diarrheal episodes lasting more than 3 days, and stool frequency on day 2 of illness [89].

AAD affects approximately $30 \%$ of patients and is frequently associated with broad-spectrum antibiotic use $[90,91]$. AAD can outlast the period of antibiotic use and makes the patient more vulnerable to infections and other diseases $[25,92]$. Positive associations between probiotics and a decrease in AAD have been reported [68, 93, 94]. However, studies were consistently limited as they were underpowered and used varying probiotic strains, formulations, and doses. The studied population had differences such as age, health conditions, and genetic factors. These factors resulted in the heterogeneity of the studies. Therefore, the extent of purported benefits remains unknown [93].

\section{Probiotics for C. difficile-associated diarrhea} Up to $30 \%$ of AAD are secondary to CDI. It is the commonest cause of infectious diarrhea in healthcare settings $[95,96]$. The care of such patients requires intensive infection control measures of isolation, contact precautions, and terminal cleaning to limit nosocomial transmission. The clinical practice guidelines for CDI in adults and children by the Society for Healthcare Epidemiology of America and the IDSA make no recommendation with regard to the administration of probiotics for the treatment and prevention of primary or recurrent CDI [49]. Meta-analyses have shown that probiotics may be effective at preventing CDI with up to $70 \%$ risk reduction $[68,69]$. However, in post hoc analysis, it was demonstrated that this large risk reduction was significant only in patients who had a higher baseline CDI risk of $>5 \%(3.1 \%$ in the robiotic group vs. $11.6 \%$ in the control group).

Risk of CDI recurrence is approximately $25 \%$, and attempts have been made to lower the recurrence rate. A randomized placebo-controlled trial showed that patients with CDI treated with $S$. boulardii plus standard antibiotics had a significantly lower relative risk of CDI recurrence than placebo plus standard antibiotics [97]. While there was a trend that $S$. boulardii could reduce CDI recurrence in patients with initial CDI and recurrent CDI, significance was demonstrated only in the latter [97]. In a double-blind, placebocontrolled trial, among patients who received high-dose enteral vancomycin ( 2 g/day), Surawiez et al. demonstrated a significant reduction $(16.7 \%$ vs. $50.0 \%$ ) in CDI recurrence when $S$. boulardii was administered [98]. However, the high-dose vancomycin arm only had 32 subjects, and most were severely ill with CDI complications such as pseudomembranous colitis. In the low dose ( $1 \mathrm{~g} /$ day) vancomycin and metronidazole arms ( $n=85$ and 53, respectively), co-administration of $S$. boulardii was not associated with reductions in CDI recurrence. The efficacy of probiotics in preventing CDI recurrence is promising, but studies are still limited by small sample sizes and the lack of consistently reproducible data $[49,69]$.

\section{Safety Considerations}

Few clinical trials have addressed the safety profile of probiotics because of the lack of safety documentation. Often, they are underpowered for this purpose [99]. However, rare events such as bacteremia and fungemia have been reported, especially in vulnerable populations such as immunocompromised patients [100]. Lastly, there have been reports where commercial probiotic strains carried antibiotic resistance genes [101]. This is a threat, especially when lateral transfer of these undesirable genes to pathogens and commensal the gut microbiota is possible. 


\section{CONCLUSIONS}

The maintenance of a healthy and diverse gut microbiota plays an important role in the prevention and acquisition of MDRO, and strategies that modulate its composition have great potential in impacting human health. This serves to reinforce antibiotic stewardship principles that limit the negative effects of antibiotics on the gut microbiota. Specific strategies include developing models for assessing the impact of various antimicrobial combinations on the gut microbiota, and promoting the development and use of such therapies with demonstrable reduced impact. Novel interventions, such as microbiota auto-banking and transplantation to perform studies for reducing colonization by MDRO, as well as developing more advanced probiotics that are reflective of the complexity of the native gut microbiota, can serve to restore gut microbiota diversity in the face of dysbiosis. As we discover more about the host protective mechanism afforded by an intact microbiota, further research should be invested in promoting the development of molecular therapeutics to mimic normal host-microbiota interactions.

The VITORA (NCT03944369) and EFFECTCPE (NCT03802461) trials are ongoing clinical trials that have been publicly registered to assess the effectiveness of the manipulation of the gut microbiota for the eradication of MDRO carriage. A trial conducted by the Memorial Sloan Kettering Cancer Center to see how different antibiotics affect the commensal bacteria existing in the intestinal tract is currently underway. With increased understanding, gut microbiota profiling through metataxonomic analysis may provide further insight into modulating microbial communities in the context of infection prevention and control.

\section{ACKNOWLEDGEMENTS}

Funding. No funding or sponsorship was received for this study or publication of this article.
Authorship. All named authors meet the International Committee of Medical Journal Editors (ICMJE) criteria for authorship for this article, take responsibility for the integrity of the work as a whole, and have given their approval for this version to be published.

Authorship Contributions. GSE Tan, HL Tay, SH Tan and TM Ng wrote the manuscript. All authors contributed to the critical revision of the final manuscript.

Disclosures. Glorijoy Shi En Tan, Hui Lin Tay, Sock Hoon Tan, Tau Hong Lee, Tat Ming $\mathrm{Ng}$ and David Chien Lye have no conflicts of interest to declare.

Compliance with Ethics Guidelines. This article is based on previously conducted studies and does not contain any studies with human participants or animals performed by any of the authors.

Open Access. This article is licensed under a Creative Commons Attribution-NonCommercial 4.0 International License, which permits any non-commercial use, sharing, adaptation, distribution and reproduction in any medium or format, as long as you give appropriate credit to the original author(s) and the source, provide a link to the Creative Commons licence, and indicate if changes were made. The images or other third party material in this article are included in the article's Creative Commons licence, unless indicated otherwise in a credit line to the material. If material is not included in the article's Creative Commons licence and your intended use is not permitted by statutory regulation or exceeds the permitted use, you will need to obtain permission directly from the copyright holder. To view a copy of this licence, visit http:// creativecommons.org/licenses/by-nc/4.0/.

\section{REFERENCES}

1. Lynch SV, Pedersen O. The human intestinal microbiome in health and disease. N Engl J Med. 2016;375(24):2369-79. 
2. Peterson J, Garges S, Giovanni M, McInnes P, Wang L, Schloss JA, et al. The NIH Human Microbiome Project. Genome Res. 2009;19(12):2317-23.

3. Araos R, D'Agata EMC. The human microbiota and infection prevention. Infect Control Hosp Epidemiol. 2019;40(5):585-9.

4. Lagier JC, Million M, Hugon P, Armougom F, Raoult D. Human gut microbiota: repertoire and variations. Front Cell Infect Microbiol. 2012;2:136.

5. Xu C, Zhu H, Qiu P. Aging progression of human gut microbiota. BMC Microbiol. 2019;19(1):236.

6. Kapourchali FR, Cresci GAM. Early-life gut microbiome-the importance of maternal and infant factors in its establishment. Nutr Clin Pract. 2020;35(3):386-405.

7. Gargiullo L, Del Chierico F, D'Argenio P, Putignani L. Gut microbiota modulation for multidrug-resistant organism decolonization: present and future perspectives. Front Microbiol. 2019;10:1704.

8. Nord CE, Heimdahl A, Kager L, Malmborg AS. The impact of different antimicrobial agents on the normal gastrointestinal microflora of humans. Rev Infect Dis. 1984;6(Suppl 1):S270-5.

9. Jakobsson HE, Jernberg C, Andersson AF, SjolundKarlsson M, Jansson JK, Engstrand L. Short-term antibiotic treatment has differing long-term impacts on the human throat and gut microbiome. PLOS ONE. 2010;5(3):e9836.

10. Bhalodi AA, van Engelen TSR, Virk HS, Wiersinga WJ. Impact of antimicrobial therapy on the gut microbiome. J Antimicrob Chemother. 2019;74(Supplement_1):6-15.

11. Nord CE, Brismar B, Kasholm-Tengve B, Tunevall G. Effect of piperacillin/tazobactam treatment on human bowel microflora. J Antimicrob Chemother. 1993;31(Suppl A):61-5.

12. Hecker MT, Aron DC, Patel NP, Lehmann MK, Donskey CJ. Unnecessary use of antimicrobials in hospitalized patients: current patterns of misuse with an emphasis on the antianaerobic spectrum of activity. Arch Intern Med. 2003;163(8):972-8.

13. Donskey CJ, Chowdhry TK, Hecker MT, Hoyen CK, Hanrahan JA, Hujer AM, et al. Effect of antibiotic therapy on the density of vancomycin-resistant enterococci in the stool of colonized patients. N Engl J Med. 2000;343(26):1925-32.

14. DiNubile MJ, Chow JW, Satishchandran V, Polis A, Motyl MR, Abramson MA, et al. Acquisition of resistant bowel flora during a double-blind randomized clinical trial of ertapenem versus piperacillin-tazobactam therapy for intraabdominal infections. Antimicrob Agents Chemother. 2005;49(8):3217-21.

15. Edlund C, Beyer G, Hiemer-Bau M, Ziege S, Lode H, Nord CE. Comparative effects of moxifloxacin and clarithromycin on the normal intestinal microflora. Scand J Infect Dis. 2000;32(1):81-5.

16. Wistrom J, Gentry LO, Palmgren AC, Price M, Nord $\mathrm{CE}$, Ljungh A, et al. Ecological effects of short-term ciprofloxacin treatment of travellers' diarrhoea. J Antimicrob Chemother. 1992;30(5):693-706.

17. Edlund C, Sjostedt S, Nord CE. Comparative effects of levofloxacin and ofloxacin on the normal oral and intestinal microflora. Scand $\mathrm{J}$ Infect Dis. 1997;29(4):383-6.

18. Ajami NJ, Cope JL, Wong MC, Petrosino JF, Chesnel L. Impact of oral fidaxomicin administration on the intestinal microbiota and susceptibility to Clostridium difficile colonization in mice. Antimicrob Agents Chemother. 2018;62(5):e02112-17. https:// doi.org/10.1128/AAC.02112-17.

19. Johnson S, Gerding DN, Louie TJ, Ruiz NM, Gorbach SL. Sustained clinical response as an endpoint in treatment trials of Clostridium difficile-associated diarrhea. Antimicrob Agents Chemother. 2012;56(8):4043-5.

20. Lew KY, Ng TM, Tan M, Tan SH, Lew EL, Ling LM, et al. Safety and clinical outcomes of carbapenem de-escalation as part of an antimicrobial stewardship programme in an ESBL-endemic setting. J Antimicrob Chemother. 2015;70(4):1219-25.

21. Tay HL, Chow A, Ng TM, Lye DC. Risk factors and treatment outcomes of severe Clostridioides difficile infection in Singapore. Sci Rep. 2019;9(1):13440.

22. Teo J, Kwa AL, Loh J, Chlebicki MP, Lee W. The effect of a whole-system approach in an antimicrobial stewardship programme at the Singapore General Hospital. Eur J Clin Microbiol Infect Dis. 2012;31(6):947-55.

23. Versporten A, Zarb P, Caniaux I, Gros MF, Drapier $\mathrm{N}$, Miller M, et al. Antimicrobial consumption and resistance in adult hospital inpatients in 53 countries: results of an internet-based global point prevalence survey. Lancet Glob Health. 2018;6(6): e619-29.

24. Palleja A, Mikkelsen KH, Forslund SK, Kashani A, Allin $\mathrm{KH}$, Nielsen T, et al. Recovery of gut microbiota of healthy adults following antibiotic exposure. Nat Microbiol. 2018;3(11):1255-65.

25. Jernberg C, Löfmark S, Edlund C, Jansson JK. Longterm ecological impacts of antibiotic administration 
on the human intestinal microbiota. ISME J. 2007;1(1):56-66.

26. Zwittink RD, Renes IB, van Lingen RA, van ZoerenGrobben D, Konstanti P, Norbruis OF, et al. Association between duration of intravenous antibiotic administration and early-life microbiota development in late-preterm infants. Eur J Clin Microbiol Infect Dis. 2018;37(3):475-83.

27. Ihm C, Sutton JD, Timbrook TT, Spivak ES. Treatment duration and associated outcomes for skin and soft tissue infections in patients with obesity or heart failure. Open Forum Infect Dis. 2019;6(6): ofz217.

28. Germanos GJ, Trautner BW, Zoorob RJ, Salemi JL, Drekonja D, Gupta K, et al. No clinical benefit to treating male urinary tract infection longer than seven days: an outpatient database study. Open Forum Infect Dis. 2019;6(6):ofz216.

29. Loo LW, Liew YX, Lee W, Lee LW, Chlebicki P, Kwa AL. Discontinuation of antibiotic therapy within 24 hours of treatment initiation for patients with no clinical evidence of bacterial infection: a 5-year safety and outcome study from Singapore General Hospital Antimicrobial Stewardship Program. Int J Antimicrob Agents. 2019;53(5):606-11.

30. Zhang L, Huang Y, Zhou Y, Buckley T, Wang HH. Antibiotic administration routes significantly influence the levels of antibiotic resistance in gut microbiota. Antimicrob Agents Chemother. 2013;57(8):3659-66.

31. Nord CE, Kager L, Heimdahl A. Impact of antimicrobial agents on the gastrointestinal microflora and the risk of infections. Am J Med. 1984;76(5A): 99-106.

32. Nord CE, Kager L, Philipson A, Stiernstedt G. Impact of imipenem/cilastatin therapy on faecal flora. Eur J Clin Microbiol. 1984;3(5):475-7.

33. Bergan T, Nord CE, Thorsteinsson SB. Effect of meropenem on the intestinal microflora. Eur J Clin Microbiol Infect Dis. 1991;10(6):524-7.

34. Cavallaro V, Catania V, Bonaccorso R, Mazzone S, Speciale A, Di Marco R, et al. Effect of a broadspectrum cephalosporin on the oral and intestinal microflora in patients undergoing colorectal surgery. J Chemother. 1992;4(2):82-7.

35. Lebel M. Pharmacokinetic properties of clarithromycin: a comparison with erythromycin and azithromycin. Can J Infect Dis. 1993;4(3):148-52.

36. Sullivan A, Edlund C, Nord CE. Effect of antimicrobial agents on the ecological balance of human microflora. Lancet Infect Dis. 2001;1(2):101-14.
37. McLaughlin M, Advincula MR, Malczynski M, Qi C, Bolon M, Scheetz MH. Correlations of antibiotic use and carbapenem resistance in enterobacteriaceae. Antimicrob Agents Chemother. 2013;57(10): 5131-3.

38. Tacconelli E, De Angelis G, Cataldo MA, Mantengoli E, Spanu T, Pan A, et al. Antibiotic usage and risk of colonization and infection with antibiotic-resistant bacteria: a hospital population-based study. Antimicrob Agents Chemother. 2009;53(10): 4264-9.

39. Quon BS, Goss CH, Ramsey BW. Inhaled antibiotics for lower airway infections. Ann Am Thorac Soc. 2014;11(3):425-34.

40. Palmer LB, Smaldone GC, Chen JJ, Baram D, Duan $\mathrm{T}$, Monteforte $\mathrm{M}$, et al. Aerosolized antibiotics and ventilator-associated tracheobronchitis in the intensive care unit. Crit Care Med. 2008;36(7): 2008-13.

41. Rattanaumpawan $P$, Lorsutthitham J, Ungprasert $P$, Angkasekwinai N, Thamlikitkul V. Randomized controlled trial of nebulized colistimethate sodium as adjunctive therapy of ventilator-associated pneumonia caused by Gram-negative bacteria. J Antimicrob Chemother. 2010;65(12):2645-9.

42. Kalil AC, Metersky ML, Klompas M, Muscedere J, Sweeney DA, Palmer LB, et al. Management of adults with hospital-acquired and ventilator-associated pneumonia: 2016 Clinical Practice Guidelines by the Infectious Diseases Society of America and the American Thoracic Society. Clin Infect Dis. 2016;63(5):e61-111.

43. Hake ME, Young H, Hak DJ, Stahel PF, Hammerberg EM, Mauffrey C. Local antibiotic therapy strategies in orthopaedic trauma: practical tips and tricks and review of the literature. Injury. 2015;46(8):1447-56.

44. Sorbara MT, Pamer EG. Interbacterial mechanisms of colonization resistance and the strategies pathogens use to overcome them. Mucosal Immunol. 2019;12(1):1-9.

45. Donskey CJ. The role of the intestinal tract as a reservoir and source for transmission of nosocomial pathogens. Clin Infect Dis. 2004;39(2):219-26.

46. Martin RM, Cao J, Brisse S et al. Molecular epidemiology of colonizing and infecting isolates of Klebsiella pneumoniae. mSphere. 2016;1(5): e00261-16. https://doi.org/10.1128/mSphere. 00261-16.

47. Gorrie CL, Mirceta M, Wick RR, Edwards DJ, Thomson NR, Strugnell RA, et al. Gastrointestinal carriage is a major reservoir of Klebsiella pneumoniae 
infection in intensive care patients. Clin Infect Dis. 2017;65(2):208-15.

48. Eiseman B, Silen W, Bascom GS, Kauvar AJ. Fecal enema as an adjunct in the treatment of pseudomembranous enterocolitis. Surgery. 1958;44(5): 854-9.

49. McDonald LC, Gerding DN, Johnson S, Bakken JS, Carroll KC, Coffin SE, et al. Clinical practice guidelines for Clostridium difficile Infection in Adults and Children: 2017 Update by the Infectious Diseases Society of America (IDSA) and Society for Healthcare Epidemiology of America (SHEA). Clin Infect Dis. 2018;66(7):e1-48.

50. van Nood E, Vrieze A, Nieuwdorp M, Fuentes S, Zoetendal EG, de Vos WM, et al. Duodenal infusion of donor feces for recurrent Clostridium difficile. N Engl J Med. 2013;368(5):407-15.

51. Lee CH, Steiner T, Petrof EO, Smieja M, Roscoe D, Nematallah A, et al. Frozen vs fresh fecal microbiota transplantation and clinical resolution of diarrhea in patients with recurrent Clostridium difficile Infection: a Randomized Clinical Trial. JAMA. 2016;315(2):142-9.

52. Hvas CL, Dahl Jorgensen SM, Jorgensen SP, Storgaard M, Lemming L, Hansen MM, et al. Fecal microbiota transplantation is superior to fidaxomicin for treatment of recurrent Clostridium difficile infection. Gastroenterology. 2019;156(5):132432.e3.

53. Staley C, Kaiser T, Vaughn BP, Graiziger CT, Hamilton MJ, Rehman TU, et al. Predicting recurrence of Clostridium difficile infection following encapsulated fecal microbiota transplantation. Microbiome. 2018;6(1):166.

54. Cheng S, Ma X, Geng S, Jiang X, Li Y, Hu L, Li J, Wang Y, Han X. Fecal microbiota transplantation beneficially regulates intestinal mucosal autophagy and alleviates gut barrier injury. mSystems. 2018;3: e00137-18. https://doi.org/10.1128/mSystems. 00137-18.

55. Woodworth MH, Hayden MK, Young VB, Kwon JH. The role of fecal microbiota transplantation in reducing intestinal colonization with antibiotic-resistant organisms: the current landscape and future directions [published correction appears in Open Forum Infect Dis. 2019 Oct 20;6(10):ofz391]. Open Forum Infect Dis. 2019;6(7):ofz288. https://doi.org/ 10.1093/ofid/ofz288.

56. Lagier JC, Million M, Fournier PE, Brouqui P, Raoult D. Faecal microbiota transplantation for stool decolonization of OXA-48 carbapenemase-producing Klebsiella pneumoniae. J Hosp Infect. 2015;90(2):173-4.
57. Bilinski J, Grzesiowski P, Sorensen N, Madry K, Muszynski J, Robak K, et al. Fecal microbiota transplantation in patients with blood disorders inhibits gut colonization with antibiotic-resistant bacteria: results of a Prospective, Single-Center Study. Clin Infect Dis. 2017;65(3):364-70.

58. Dinh A, Fessi H, Duran C, Batista R, Michelon H, Bouchand F, et al. Clearance of carbapenem-resistant Enterobacteriaceae vs vancomycin-resistant enterococci carriage after faecal microbiota transplant: a prospective comparative study. J Hosp Infect. 2018;99(4):481-6.

59. Singh R, de Groot PF, Geerlings SE, Hodiamont CJ, Belzer C, Berge I, et al. Fecal microbiota transplantation against intestinal colonization by extended spectrum beta-lactamase producing Enterobacteriaceae: a proof of principle study. BMC Res Notes. 2018;11(1):190.

60. Saidani N, Lagier JC, Cassir N, Million M, Baron S, Dubourg G, et al. Faecal microbiota transplantation shortens the colonisation period and allows re-entry of patients carrying carbapenamase-producing bacteria into medical care facilities. Int J Antimicrob Agents. 2019;53(4):355-61.

61. Wittekamp BH, Plantinga NL, Cooper BS, LopezContreras J, Coll P, Mancebo J, et al. Decontamination strategies and bloodstream infections with antibiotic-resistant microorganisms in ventilated patients: a randomized clinical trial. JAMA. 2018;320(20):2087-98.

62. Huttner BD, de Lastours V, Wassenberg M, Maharshak N, Mauris A, Galperine T, et al. A 5-day course of oral antibiotics followed by faecal transplantation to eradicate carriage of multidrug-resistant Enterobacteriaceae: a randomized clinical trial. Clin Microbiol Infect. 2019;25(7):830-8.

63. Tacconelli E, Mazzaferri F, de Smet AM, Bragantini D, Eggimann P, Huttner BD, et al. ESCMID-EUCIC clinical guidelines on decolonization of multidrugresistant Gram-negative bacteria carriers. Clin Microbiol Infect. 2019;25(7):807-17.

64. Ritchie ML, Romanuk TN. A meta-analysis of probiotic efficacy for gastrointestinal diseases. PLoS ONE. 2012;7(4):e34938.

65. Underwood MA. Probiotics and the prevention of necrotizing enterocolitis. J Pediatr Surg. 2019;54(3): 405-12.

66. Sawh SC, Deshpande S, Jansen S, Reynaert CJ, Jones PM. Prevention of necrotizing enterocolitis with probiotics: a systematic review and meta-analysis. PeerJ. 2016;4:e2429. 
67. Aceti A, Gori D, Barone G, Callegari ML, Di Mauro A, Fantini MP, et al. Probiotics for prevention of necrotizing enterocolitis in preterm infants: systematic review and meta-analysis. Ital J Pediatr. 2015;41:89.

68. Pattani R, Palda VA, Hwang SW, Shah PS. Probiotics for the prevention of antibiotic-associated diarrhea and Clostridium difficile infection among hospitalized patients: systematic review and meta-analysis. Open Med. 2013;7(2):e56-67.

69. Goldenberg JZ, Yap C, Lytvyn L, Lo CK, Beardsley J, Mertz D, et al. Probiotics for the prevention of Clostridium difficile-associated diarrhea in adults and children. Cochrane Database Syst Rev. 2017;12: CD006095.

70. Johanson WG, Pierce AK, Sanford JP. Changing pharyngeal bacterial flora of hospitalized patients. Emergence of gram-negative bacilli. N Engl J Med. 1969;281(21):1137-40.

71. Stoutenbeek CP, van Saene HK, Miranda DR, Zandstra DF. The effect of selective decontamination of the digestive tract on colonisation and infection rate in multiple trauma patients. Intensive Care Med. 1984;10(4):185-92.

72. Vadhwana B, Pouzi A, Surjus Kaneta G, Reid V, Claxton D, Pyne L, et al. Preoperative oral antibiotic bowel preparation in elective resectional colorectal surgery reduces rates of surgical site infections: a single-centre experience with a cost-effectiveness analysis. Ann R Coll Surg Engl. 2020;102(2):133-40.

73. Toh JWT, Phan K, Hitos K, Pathma-Nathan N, ElKhoury T, Richardson AJ, et al. Association of mechanical bowel preparation and oral antibiotics before elective colorectal surgery with surgical site infection: a network meta-analysis. JAMA network open. 2018;1(6):e183226.

74. Koskenvuo L, Lehtonen T, Koskensalo S, Rasilainen S, Klintrup K, Ehrlich A, et al. Mechanical and oral antibiotic bowel preparation versus no bowel preparation for elective colectomy (MOBILE): a multicentre, randomised, parallel, single-blinded trial. Lancet (London, England). 2019;394(10201): 840-8.

75. (FAO) FaAOotUN, World, (WHO) HO. Joint FAO/ WHO expert consultation on evaluation of health and nutritional properties of probiotics in food including powder milk and live lactic acid bacteria. http://www.fao.org/3/a-a0512e.pdf. Accessed 1 May 2020.

76. Gibson GR, Hutkins R, Sanders ME, Prescott SL, Reimer RA, Salminen SJ, et al. Expert consensus document: the International Scientific Association for Probiotics and Prebiotics (ISAPP) consensus statement on the definition and scope of prebiotics. Nat Rev Gastroenterol Hepatol. 2017;14(8): 491-502.

77. Manley KJ, Fraenkel MB, Mayall BC, Power DA. Probiotic treatment of vancomycin-resistant enterococci: a randomised controlled trial. Med J Aust. 2007;186(9):454-7.

78. Szachta P, Ignyś I, Cichy W. An evaluation of the ability of the probiotic strain Lactobacillus rhamnosus GG to eliminate the gastrointestinal carrier state of vancomycin-resistant enterococci in colonized children. J Clin Gastroenterol. 2011;45(10):872-7.

79. Eggers S, Barker AK, Valentine S, Hess T, Duster M, Safdar N. Effect of Lactobacillus rhamnosus HNO01 on carriage of Staphylococcus aureus: results of the impact of probiotics for reducing infections in veterans (IMPROVE) study. BMC Infect Dis. 2018;18(1):129.

80. Tannock GW, Tiong IS, Priest P, Munro K, Taylor C, Richardson A, et al. Testing probiotic strain Escherichia coli Nissle 1917 (Mutaflor) for its ability to reduce carriage of multidrug-resistant $E$. coli by elderly residents in long-term care facilities. J Med Microbiol. 2011;60(Pt 3):366-70.

81. Salomão MC, Heluany-Filho MA, Menegueti MG, Kraker ME, Martinez R, Bellissimo-Rodrigues F. A randomized clinical trial on the effectiveness of a symbiotic product to decolonize patients harboring multidrug-resistant Gram-negative bacilli. Rev Soc Bras Med Trop. 2016;49(5):559-66.

82. Vandeputte D, Falony G, Vieira-Silva S, Wang J, Sailer M, Theis $S$, et al. Prebiotic inulin-type fructans induce specific changes in the human gut microbiota. Gut. 2017;66(11):1968-74.

83. Dewulf EM, Cani PD, Claus SP, Fuentes S, Puylaert PG, Neyrinck AM, et al. Insight into the prebiotic concept: lessons from an exploratory, double blind intervention study with inulin-type fructans in obese women. Gut. 2013;62(8):1112-21.

84. Terrin G, Scipione A, De Curtis M. Update in pathogenesis and prospective in treatment of necrotizing enterocolitis. Biomed Res Int. 2014;2014:543765.

85. Patel RM, Kandefer S, Walsh MC, Bell EF, Carlo WA, Laptook AR, et al. Causes and timing of death in extremely premature infants from 2000 through 2011. N Engl J Med. 2015;372(4):331-40.

86. Patel RM, Underwood MA. Probiotics and necrotizing enterocolitis. Semin Pediatr Surg. 2018;27(1): 39-46. 
87. Sharma R, Hudak ML. A clinical perspective of necrotizing enterocolitis: past, present, and future. Clin Perinatol. 2013;40(1):27-51.

88. Szajewska H, Mrukowicz JZ. Probiotics in the treatment and prevention of acute infectious diarrhea in infants and children: a systematic review of published randomized, double-blind, placebo-controlled trials. J Pediatr Gastroenterol Nutr. 2001;33(Suppl 2):S17-25.

89. Allen SJ, Martinez EG, Gregorio GV, Dans LF. Probiotics for treating acute infectious diarrhoea. Cochrane Database Syst Rev. 2010;11:CD003048.

90. McFarland LV. Epidemiology, risk factors and treatments for antibiotic-associated diarrhea. Dig Dis. 1998;16(5):292-307.

91. Barbut F, Meynard JL. Managing antibiotic associated diarrhoea. BMJ. 2002;324(7350):1345-6.

92. Croswell A, Amir E, Teggatz P, Barman M, Salzman NH. Prolonged impact of antibiotics on intestinal microbial ecology and susceptibility to enteric Salmonella infection. Infect Immun. 2009;77(7): 2741-53.

93. Cremonini F, Di Caro S, Nista EC, Bartolozzi F, Capelli G, Gasbarrini G, et al. Meta-analysis: the effect of probiotic administration on antibiotic-associated diarrhoea. Aliment Pharmacol Ther. 2002;16(8):1461-7.

94. Hempel S, Newberry SJ, Maher AR, Wang Z, Miles JN, Shanman R, et al. Probiotics for the prevention and treatment of antibiotic-associated diarrhea: a systematic review and meta-analysis. JAMA. 2012;307(18):1959-69.

95. Jawa RS, Mercer DW. Clostridium difficile-associated infection: a disease of varying severity. Am J Surg. 2012;204(6):836-42.

96. Kachrimanidou M, Malisiovas N. Clostridium difficile infection: a comprehensive review. Crit Rev Microbiol. 2011;37(3):178-87.

97. McFarland LV, Surawicz CM, Greenberg RN, Fekety $\mathrm{R}$, Elmer GW, Moyer KA, et al. A randomized placebo-controlled trial of Saccharomyces boulardii in combination with standard antibiotics for Clostridium difficile disease. JAMA. 1994;271(24):1913-8.

98. Surawicz CM, McFarland LV, Greenberg RN, Rubin M, Fekety R, Mulligan ME, et al. The search for a better treatment for recurrent Clostridium difficile disease: use of high-dose vancomycin combined with Saccharomyces boulardii. Clin Infect Dis. 2000;31(4):1012-7.

99. Bafeta A, Koh M, Riveros C, Ravaud P. Harms reporting in randomized controlled trials of interventions aimed at modifying microbiota: a systematic review. Ann Intern Med. 2018;169(4): 240-7.

100. Didari T, Solki S, Mozaffari S, Nikfar S, Abdollahi M. A systematic review of the safety of probiotics. Expert Opin Drug Saf. 2014;13(2):227-39.

101. Wong A, Ngu DY, Dan LA, Ooi A, Lim RL. Detection of antibiotic resistance in probiotics of dietary supplements. Nutr J. 2015;14:95. 